\title{
Christian Lay Theodicy and the Cancer Experience
}

\author{
Eric Jason Silverman \\ Christopher Newport University \\ M. Elizabeth Lewis Hall \\ Biola University \\ Jamie Aten \\ Wheaton College \\ Laura Shannonhouse \\ Georgia State University \\ Jason McMartin \\ Biola University
}

\begin{abstract}
How do religious sufferers actually perceive the apparent tension between belief in God and painful suffering? Too often the problem of evil has been treated merely as a purely abstract problem, as a metaphysical puzzle to be solved. Yet, the tension between suffering and religious belief is also a human experience that should be examined in the light of actual testimony. Therefore, our interdisciplinary investigative team arranged a series of interviews with self-identified Evangelical Christians who had been diagnosed with cancer at some point in their lives to investigate their perceptions about why their God allowed them to suffer through cancer. By systematically examining their observations concerning their experience with the apparent evil of suffering, we hoped to see whether the aggregate of their observations concerning their suffering corroborated, coincided with, or conflicted with the traditional theodical explanations offered by philosophers. Therefore, our study has two main facets: first, to gather information concerning how typical religious lay sufferers make sense of their experience. Second, to see whether the results of these interviews corroborate or undermine any of the major philosophical responses to the problem of evil.
\end{abstract}

Journal of Analytic Theology, Vol. 8, August 2020

10.12978/jat.2020-8.1808-65001913

(C) 2020 Eric Jason Silverman, et al. • (C) 2020 Journal of Analytic Theology 


\section{The Philosophical Problem of Evil}

In philosophy of religion, it is well-known that the problem of evil centers on the tension between and potential incompatibility of two claims such as:

1) There exists a perfectly good, loving, all-powerful, all-knowing God.

2) Evil exists-such as personal suffering embodied in the experience of cancer.

The atheologian's response to these two claims is to argue that the existence of evil in the second claim is incompatible with the first claim or at least offers considerable evidence against the first claim (Mackie 1982). Two broad types of theist responses to this problem are: theodical responses and skeptical theistic responses. A theodical response generally adds a third statement to demonstrate that the first two statements are not truly incompatible with one another. One generic theodical response is:

3) A perfectly good, loving, all-powerful, all-knowing God allows evil to exist for a good, loving, and morally sufficient reason (Plantinga 1974).

Statement three demonstrates the compatibility of statements one and two while allowing the theist to acknowledge uncertainty and mystery concerning why God allows evil. Yet, since it does not specify a reason for evil's existence, it is easy for the atheologian to reject it as implausible or to demand further argumentation. When a more specific theodicy is offered the precise nature of the reason for allowing evil varies, but some possible responses are: ${ }^{1}$

3a) God allows evil to occur, because it is a necessary consequence for allowing the great good of creaturely free will (Plantinga 1974).

3b) God allows evil to occur, because it is a necessary condition for the great good of qualitatively superior types of creaturely moral development (Hick 2010). ${ }^{2}$

3c) God allows evil to occur, because it is a necessary condition for allowing the great good of qualitatively superior kinds of spiritual growth and/or relational intimacy with God (Stump 2012).

\footnotetext{
${ }^{1}$ There are other noteworthy responses to the problem of evil, such as Peter van Inwagen's 'natural laws' explanation for evil. Yet, we did not design our interviews with this potential response in mind (Inwagen 1996).

${ }^{2}$ The most influential contemporary moral development theodicy has been formulated by John Hick. While he is appropriately viewed as the foremost contemporary advocate of a soul-making/moral development theodicy, there are also less central claims in his book that suggest that the existence of evil allows superior relational development as well as spiritual development. We have separated these three related claims, but they are all arguably found in Hick (Hick 2010).
} 
3d) God allows evil to occur, because it is necessary for the great good of bringing humans into qualitatively superior kinds of relationships with other human individuals and the community. ${ }^{3}$

3e) God allows evil to occur (even causing suffering in some circumstances), because it is necessary achieve the great goods of punishing sin and upholding justice (Alston 1996).

In additional to these singular explanations for evil, a more complex theodical strategy would be to combine multiple explanations for evil since God could have many, simultaneous reasons for allowing evil that are either individually or jointly sufficient to justify its existence.

While theodical responses to the problem of evil focus upon demonstrating the compatibility of statements one and two, a second broad type of theist response to the problem of evil attempts to deny or undermine the background assumption to the problem of evil that humans are in a position to judge whether the existence of evil is incompatible with the existence of God (Wykstra 1996). If this skeptical response is successful, then the atheologian's inference to the non-existence of God from the combination of statements one and two is undermined even without further demonstration of the statements' compatibility. Rather than reconciling the two statements, skeptical theism seeks to undermine the legitimacy of the atheologian's inference from the existence of evil to the non-existence of God.

According to skeptical theistic arguments, since humans are finite beings with a finite and often flawed perspective, we are not in a position to make inferences about whether a theistic God might have morally sufficient reasons for allowing suffering. For example, Stephen Wykstra argues,

The observed sufferings in the world do require us to say that there are outweighing goods connected to them that are entirely outside our ken, but this is not an additional postulate: it was implicit in theism (taken with a little realism about our cognitive powers) all along. If we have realized the magnitude of the theistic proposal, cognizance of suffering thus should not in the least reduce our confidence that it is true (Wykstra 1984, 160).

This type of skeptical theism emphasizes the comparative magnitude of any potential God's knowledge and power to the obvious limitedness of our own abilities. Thus, it acknowledges the atheologian's observation - that evil obviously exists-and even allows that evil exists for which we cannot identify a "good divine purpose." Yet, the skeptical theist claims that this state of affairs is to be expected. It is unsurprising that evil events happen for which we cannot identify a "good divine purpose," in order to do so we would need to have enormously enhanced cognitive capacities. Therefore, while evil exists, God may have all sorts of overriding reasons for allowing evil that we should realize that our limited perspective would not allow us to discern.

\footnotetext{
${ }^{3}$ While I am not aware of any theodicy that focuses upon the importance of relational goods exclusively, significant themes in both Hick's and Stump's theodicies focus upon relational goods. Therefore, it seemed worthy of attention as its own distinct category of responses.
} 
Accordingly, no third statement is needed to explain the compatibility of theism with evil in this world.

\section{Overview of the Study}

Twenty-nine self-described Evangelical Christians who had received a cancer diagnosis at some point in their lives were interviewed for our study. Although data saturation was achieved after 20 interviews, additional interviews were conducted to include a greater variety of cancer diagnoses and stages. Since all interviewees identified as Evangelical Christians, it was expected that they would assent to belief in a theistic God as expressed in statement one of the problem of evil-or at least assent to a reasonably similar belief. It was also expected that each interviewee would assent to statement two and see their cancer experience as a dramatic, personal instance of an evil event. The explicit existential threat of cancer guarantees that the individual has much at stake in the experience. Furthermore, the pain and suffering that typically accompanies either the cancer itself or cancer treatments makes it a compelling example of evil experienced in a deeply personal way.

The slow and drawn out nature of cancer experiences gives the sufferer considerable opportunity for reflection. The cancer experience typically spans years including diagnosis, treatment, and follow up testing for recurrence when treatment is initially successful. The experience often includes an unclear long-term prognosis, multiple series of cancer treatments and staging tests, as well as follow up tests to detect potential cancer recurrence. Furthermore, these tests, treatments, and medical visits interrupt the individual's normal schedule and responsibilities making additional temporal and mental space for reflection. Therefore, the nature of the cancer experience allows considerable time and numerous occasions for reflection upon the implications of the experience-for asking "why?" and "what does this mean?" Cancer provides an especially good opportunity for thinking about the issues at the heart of the problem of evil. While most of our interviewees had already reflected upon their cancer experiences on their own, our extended interviews with them were designed to give them an additional opportunity to consider their experiences in an open-ended discussion that was designed to avoid any predetermined conclusions.

Our team was interested in seeing what explanations, meanings, and implications our interviewees attributed to their experiences. We were interested in seeing whether interviewees revised their view of God in light of their suffering, whether they held an explanation reconciling their suffering with their religious beliefs, or whether they simply did not believe that personal suffering was in tension with their religious beliefs. If there were consistent patterns in the responses given by Christian cancer sufferers, it might help identify a distinctly Christian response to the problem of evil. Furthermore, if there were recurring patterns in the types of goods experienced by our interviewees in the midst of their cancer experiences, it might offer some limited evidence in favor of such theodical answers.

Evangelicalism is a cross denominational movement within contemporary Protestantism distinguished by theological conservatism, the importance of personal 
subjective religious experience, and belief in salvation by grace alone. As such, we might expect that there should be no single collective response to the problem of evil as there are no authoritative teachings concerning the nature of evil beyond the individual believer's personal interpretation of the Bible. This lack of a single explanation for evil is an implication of the traditional Protestant doctrine known as "The Priesthood of all Believers." Within the theological context of broad Christian orthodoxy, this doctrine denies a unique authoritative status for church councils or the clergy over the laity when interpreting religious matters. Therefore, there is no specific evangelical dogma addressing the problem of evil and suffering. However, there may be influential Christians such as Billy Graham or C. S. Lewis, whose views might be held with a quasi-authoritative status among some sub-groups of evangelicals.

\section{Methods}

Our interdisciplinary investigative team includes two psychologists, a professional counselor, a philosopher, and a theologian. We interviewed twenty-nine selfidentified Evangelical Christians who had received a cancer diagnosis at some point in their life to examine the significance, effect, and personal meaning each attributed to the experience. We examined our interviews focusing upon six distinct types of explanations for/meanings of evil: trusting God in mystery, free will, moral development, spiritual growth, growth in human relationships/community, and punishment. These categories were meant to correspond loosely to six philosophical responses to the existence of evil:

1. Trusting God in Mystery. The idea that we may not know why suffering/evil occurs, but that the proper response is to trust God. Claims that roughly correspond to generic theodical statement 3 . However, as we shall see, some of these meanings for suffering might alternatively be interpreted as a kind of skeptical theism.

2. Free Will. The idea that suffering/evil occurs due to the choices of individual people other than God. Claims that roughly correspond to theodical statement 3a.

3. Moral Development. The idea that suffering/evil brings about—or is at least an opportunity to bring about- human moral improvement. Claims that roughly correspond to theodical statement $3 \mathrm{~b}$.

4. Spiritual Growth. The idea that suffering/evil brings about-or is at least an opportunity to bring about- spiritual growth. Claims that roughly correspond to theodical statement 3c.

5. Relational/Communal Growth. The idea that suffering/evil brings aboutor is at least an opportunity to bring about-improved human relationships. Claims that roughly correspond to theodical statement $3 \mathrm{~d}$.

6. Punishment. The idea that suffering is actively caused by God in order to maintain some moral ideal. Such claims roughly correspond to theodical statement $3 \mathrm{e}$. 
We coded relevant responses from our interviewees in these categories, noted the number of each type of response for each interviewee, and the predominant-most frequently cited-meaning made for suffering in each interviewee. ${ }^{4}$ Among our study's goals was to understand which responses to the problem of evil-if anyreligious lay people embraced when reflecting upon their personal experience of suffering and whether certain responses correlated with higher degrees of wellbeing, life meaning, life satisfaction, and current religiosity. We also administered surveys to ascertain life meaning and life satisfaction prior to approximately hourlong one on one interviews. ${ }^{5}$ These prolonged interviews ensured that our interviewees were unable to give brief, shallow narratives about their cancer experience without further in-depth explanation and reflection. We believe these practices generally resulted in examining each individual's genuine experiences of suffering rather than a shallow recitation of what an interviewee viewed as "the Christian" position on the matter.

\section{Interviewees}

We used a cancer support group based in a large Southern Californian church to invite religious cancer sufferers to participate in the study. To be eligible for our study, participants needed to currently self-identify as Evangelical Christian and to have received a cancer diagnosis at any point during their lifetime in a way that was significant enough for them to be involved in a support group. We interviewed 20 women and 9 men. They had a wide range in educational levels from high school graduate to post-graduate degree, with a disproportionately high number having college degrees $(75.8 \%$ had at least an Associate's Degree and 58.6\% had at least a Bachelor's Degree). Their educational level breakdown was: High School (2), Some College but no degree completed (5), Associate's Degree (5), Bachelor's Degree (12), Post-Graduate or Professional Degree (5). Time between participant's cancer diagnosis and interview ranged from one to thirty-three years with an average time of 7.8 years. A wide range of cancer types were represented with the largest groups being: breast cancer (13), prostate cancer (7), and colon cancer (3).

\footnotetext{
${ }^{4}$ The primary investigator of the overall study trained a research assistant on the coding procedure, and both independently coded two interviews as a pilot. Reliability before comparison and discussion of the coding was $57.4 \%$ (Cohen's Kappa $=.547$ ), indicating moderate consensus among raters (Landis $\&$ Koch, 1977). An additional twenty percent of the interviews were then independently coded, and the reliability achieved $75.7 \%$ agreement (Cohen's Kappa $=.748$ ), indicating substantial consensus among raters (Landis \& Koch, 1977). While this is lower than the $80 \%$ recommended by Krippendorff (2013), it should be noted that the coding system was extensive, complex, and abstract (i.e. 641 units of analysis in the sub-sample). Schreier (2012) argues that 75\% agreement can be acceptable when coding involves interpretation, rather than merely counting manifest variables.

5 Our meanings associated with cancers may also be shaped by what Susan Sontag calls "mythologies"- the patterns of symbolisms, moral meanings, cultural associations, emotional reactions, etc., that build up around them (Sontag 2001). For example, breast cancer and perceived loss of femininity might be such a mythology. Lung cancer and the sense of moral approprobation that might be associated with the self-destruction of a smoker. Of course, not all cancers bring such complex mythologies.
} 
The average age of our interviewees was 60.4 , with a range from 42 to 77 . The sample was predominantly European American (22), with the remainder Asian/Asian American (3), African American (1), Hispanic (1), and mixed ethnicity (2). Twenty (69\%) were married, eight (28\%) were divorced, and one (3\%) was widowed. Cancer diagnoses represented the full range of staging. Current health also included a full range of results from ongoing cancer with a terminal prognosis to longterm cancer survivor with no sign of active disease.

\section{Interview Content}

The core interview questions at the heart of each hour long interview:

1. Tell me about your cancer experience, when you were diagnosed, and how that happened.

2. What was helpful to you during the time around your diagnosis [for the sake of coping]?

3. What were your interactions with God like around the time of diagnosis?

4. Is your spiritual life any different now after having had cancer?

5. When you think of your cancer experience, why do you think it occurred? Why did you have to go through that?

6. Do you think your view of the world or life has changed from before you had cancer?

7. Has your view of yourself changed?

8. Has your view of other people changed from before the cancer to now?

9. Has your view of God changed as a result of your cancer experience?

10. How do you think your cancer affected those around you?

11. Have there been moments when you have experienced some tension between your Christian beliefs and your cancer diagnosis?

12. How would you respond if someone were to ask you now, "Why did you get cancer?"

13. Do you feel that your life has meaning and significance?

14. Have your life goals changed since you had cancer?

15. How do you see your cancer experience fitting into your overall life?

16. What role, if any, do you think God had in your cancer?

17. Did you ever find yourself questioning God's goodness or His power or His knowledge [during or resulting from your cancer experience]?

In addition to the core interview questions, the interviewer improvised appropriate follow up questions to encourage elaboration. The interviewer was also permitted to skip questions if it was judged that a previous answer served to answer the skipped question. 


\section{Limitations of the Study}

Although the experiences of our interviewees will corroborate some strategies for responding to evil, any conclusion based upon our data must remain quite humble. For example, even if every interviewee identified a certain benefit from their cancer experience, such a result would not prove that such suffering was the only way to attain such a benefit or that all suffering in general has such benefits. Furthermore, the total number of participants in our interviews is modest. Finally, there are risks that unidentified factors may have skewed the interpretations of our interview group concerning their cancer experience. Accordingly, the results of these interviews can only serve as single piece of defeasible evidence in the larger problem of evil debates. Similarly, even if no interviewee identifies a particular benefit from their cancer experience coinciding with a particular response to the problem of evil, this result might not demonstrate that no such benefit was received, but merely that our interviewees did not perceive such benefits.

Despite these limitations, our investigations can yield useful results that are relevant to the problem of evil. One informative result would be if a large proportion of the interviewees reported benefits stemming from their cancer experiences that coincided with a particular theodical response. If $100 \%$ of our interviewees reported profound spiritual insights and renewed religious vigor resulting from their experiences, this finding would provide some corroborating evidence in favor of such "spiritual growth" theodicies. ${ }^{6}$ It would be the sort of result-at least approximately - that we would expect to be the case if spiritual growth were God's reason for allowing such suffering. Conversely, if none of our interviewees experienced spiritual growth stemming from their cancer experience, this result would reduce the plausibility of such theodical explanations since this response cites a sort of benefit that we would have expected at least some of our interviewees to experience.

Another informative result would be if few of the interviewees accepted their cancer experience as a genuine example of evil. Such first-person experiences are data that must fit into philosophical arguments if those arguments are to accurately reflect the way people experience the world. Therefore, it is important to consider what interpretations and meanings people actually experiencing the phenomenon in question-suffering-find plausible, intuitive, and experientially significant when investigating the problem of evil.

\section{Introduction to Results}

Our interviews found several results that are relevant to the problem of evil. First, $79 \%$ of interviewees had at least one response that fit into the "Trust God in Mystery" category. Similarly, we found that $52 \%$ of our respondents did not judge that their

\footnotetext{
${ }^{6}$ For simplicity's sake, we do not emphasize the distinction between a full "theodicy" and a mere "defense" as emphasized by thinkers like Alvin Plantinga. The distinction did not seem to have significant implications for our research.
} 
cancer experience was in tension with their religious beliefs even when explicitly asked or later when given a second opportunity to discuss doubts about God's character or power. ${ }^{7}$ This group did not merely claim that they found ways to reconcile tension between their experience and their beliefs. Instead, they did not even perceive an initial apparent tension between theistic beliefs and their painful cancer experiences that would be in need of reconciliation. There is some question whether these results are best interpreted as a generic theodicy as in theodical statement 3 or as a kind of skeptical theism.

A second significant finding is that a high portion of our interviewees, 83\% reported specific examples of beneficial personal growth-moral, spiritual, or relational-that resulted from their cancer experience. When asked about their cancer experience's effect upon various aspects of their lives they identified at least one example of a benefit to the self, despite the fact that we did not ask them to identify benefits rather than harms. Depending on one's accompanying value theory and whether such benefits might have been otherwise achieved, these benefits might provide a morally sufficient reason for the existence of suffering. Our interviewees frequently described experiencing the kind of benefits at the heart of John Hick's soulmaking theodicy and Eleonore Stump's "spiritual growth" theodicy, providing at least some corroborating evidence for such views (Hick 2010 and Stump 2012). Experiences common to our interviewees were similar to what such theodicies would predict.

Third, our interviews found little or no corroboration for free will style theodical responses. Free will simply was not an important topic to most of our interviewees in making sense of their cancer experience. However, for reasons that will be discussed, this lack of corroborating evidence might be best understood as neutral concerning free will theodicies rather than actual counter-evidence against free will style responses. ${ }^{8}$

\section{Discussion of Result: Majority of Interviewees Perceive No Tension Between Cancer Experience and Theistic Christian Beliefs}

One important and unanticipated result is that the majority of interviewees-52\%perceived no tension between their cancer experience and their religious beliefs, even when directly asked. Unlike most philosophers-both theist and atheist-who accept that there is at least apparent tension between the existence of a theistic God and the existence of evil, the majority of interviewees did not perceive apparent tension between their suffering and the existence of God. While many religious

\footnotetext{
${ }^{7}$ Question 11 directly asked the interviewee whether they perceived tension between Christian beliefs and their cancer diagnosis. Question 17 asked if the interviewee questioned or doubted God's goodness or power during the cancer experience. $52 \%$ of our interviewees answered both questions negatively. An additional $13.7 \%$ claimed that they did not perceive any tension between their cancer experience and their beliefs, but later described experiencing doubts about God's goodness or power.

$87 \%$ of our interviewees had no answers from the six coded categories.
} 
thinkers have offered strategies for reconciling theistic belief with suffering, these interviewees did not even perceive a need to reconcile these claims. ${ }^{9}$

There are numerous potential ways to explain this result. One possibility is that the average layperson is simply uninterested in having a coherent set of beliefs about the world. Obviously, the average less educated layperson is less interested in and less equipped to possess a fully coherent set of beliefs about metaphysical issues than a professional academic. Yet, it is unlikely that the average person is completely uninterested in reconciling two issues of such importance: their religious beliefs and a major, painful, potentially life altering challenge to their health and existence. Furthermore, our interviewees possessed an above average educational level, and were generally well educated with the median participant possessing a Bachelor's degree, so it is unlikely that they were intellectually unsuited to see the apparent tension between the existence of God and the existence of evil. Therefore, while disinterest in a coherent worldview or lack of intelligence to perceive such tension is a possible partial explanation, we are hesitant to accept this account as the primary explanation for this result.

A more plausible explanation for our interviewees' lack of perceived tension between the existence of God and their experience with the evil of cancer is that most Christians already possess belief structures that they believe reconcile evils in physical experience with the existence of God. Since Christians believe in an immaterial God, that spiritual and moral development are transcendent concerns that last beyond this current existence, and in the hope of a blessed afterlife, they already accept the existence of the types of goods that might provide a morally sufficient reason to justify the existence of evil. For example, they may believe that earthly suffering is necessary for spiritual growth that results in an improved eternal state or that moral development is obviously more important than earthly life itself. ${ }^{10}$ They may believe that being true to their faith is so important that martyrdom is preferable to denying their religion. Since atheists reject such beliefs and value structures, the problem of evil seems far more serious from their point of view.

Furthermore, most interpretations of Christianity accept that physical suffering is to be expected. After all, the New Testament teaches that the most innocent person to walk the earth was betrayed by a close friend, abandoned by most of his friends, rejected by the religious leaders of his ethnic group, brutally beaten, whipped, publicly humiliated, and unjustly executed with the approval of the day's political authorities. There are many other biblical suffering narratives including: the sufferings of Job, the sufferings of Joseph who is kidnapped into slavery, the New

\footnotetext{
${ }^{9}$ One important implication of this finding is that it raises the possibility that the problem of evil and suffering is primarily an abstract "ivory tower" problem rather than a real life problem. Our grant team has a paper investigating this possible implication at length (Hall et al 2018).

${ }^{10}$ Interestingly, these are similar core beliefs found in Immanuel Kant's "Moral Religion." According to Kant, belief in God, the Soul, and the Afterlife make it rational for people to make sacrificial-even deeply sacrificial moral choices-because there is hope that their sacrifices may be compensated in the afterlife. In a similar way, belief in the possibility of future heavenly goods makes it possible to believe or at least hope that there are greater goods that could outweigh suffering in this life (Kant 2002).
} 
Testament's account of violent persecutions against the early church and the apostles, etc.

Since most Christians believe that suffering in this world is to be expected, but also that earthly well-being is not the greatest good, the perceived conflict undergirding the problem of evil may simply seem trivial in a way that it would not seem to "bare theists" or skeptics. Accordingly, while most Christians accept that physical suffering and physical death are genuine evils, neither category is viewed as the most serious type of evil (Matthew 10:28). Therefore, such Christians might view evil in this world as less significant than scholars often believe and believe that it is so obviously justified in light of greater goods such as eternal life that there is no great tension to resolve between the existence of God and human suffering. ${ }^{11}$

Finally, there are limitations to our research methods. Since our screening methods required that our interviewees currently identify as Evangelical Christian, it is possible that a disproportionate number of cancer sufferers who did perceive an extreme incompatibility between suffering and belief in God might no longer identify as Christian and thereby be ineligible for our interviews.

\section{Representative Quotations denying tension between Christianity and Cancer}

Interviewer: . . . Have you ever experienced any tension between your Christian beliefs and your cancer diagnosis? Was it ever an issue for you from a spiritual perspective?

Interviewee: Like why me, or why is God doing this to me? Never

Interviewer: Sure, never, it never came up. No questions about God's goodness, God's power?

Interviewee: Never, no it's good. It's the world it's broken.-[Participant 6]

Interviewer: Did you ever experience any tension between your Christian beliefs and the fact that you have cancer?

Interviewee: Not at all, not at all. In fact

Interviewer: Did you ever ask why or?

Interviewee: I never asked why me, never asked why me. That was. . .

\footnotetext{
${ }^{11}$ It is also possible that a different sub-group of Christians would have perceived greater tension between Christian theism and the experience of physical suffering. For example, a small minority of churches teach that faithful Christians should expect direct divine intervention to prevent suffering and should expect a full life of health and financial comfort (Copeland 2012). The tensions presented by the problem of evil may be far more salient to such Christians in times of suffering.
} 
Interviewer: Never question God's goodness?

Interviewee: Uh um, I felt really at peace with everything. In fact, I think for me everything was more positive.-[Participant 12]

Interviewer: ... Let me ask you another question. Um, at any point during your own cancer treatment did you experience any tension between kind of your Christianity and your cancer?

Interviewee: No. none at all.

Interviewer: Did you ever have occasion to question God's goodness, his power, his knowledge??

Interviewee: No, uh, I knew that um, that God ... you know. .. He didn't say 'you can't get sick.' Uh, He ... although you look at Paul and ... and you know ... and Job ... and I believe I'm right here ... Paul had an affliction that ... I don't know if God put it there but he had it and God didn't take it away. And Job lost everything and didn't refute God. So I know that uh, we have free will and we have choices.-[Participant 19]

\section{Discussion of Result: Low Focus on Free Will Explanations}

At least as far back as St. Augustine of Hippo theists have cited the importance of free will to explain suffering(Augustine 1960). Furthermore, some other theodicies presuppose the existence of human free will as a necessary condition for creating the greater good at the heart of their theodicy. When theodicists argue that a superior type of moral, spiritual, or relational progress is only possible in a world where evil and suffering exists, it is sometimes assumed that one of the superior aspects of such progress is that it is freely chosen by the agent rather than involuntarily accomplished by divine fiat.

Yet, only $28 \%$ of interviewees discussed free choice in connection to their cancer experience, and only $7 \%$ held free will explanations as their predominant explanation of their cancer experience. Answers which explained their cancer experience in terms of their own choices or the choices of other humans were identified as free choice responses. In principle, explanations of cancer that traced it to demonic activity would also have qualified but no such explanation occurred in our interviews. So, while free will is a prominent background consideration in a range of theodicies, relatively few interviewees directly discussed it. The few who did were typically concerned with the possibility that their own diet and lifestyle choices may have contributed to developing cancer, although one interviewee attributed her uterine cancer largely to the choices of her repeatedly unfaithful husband who exposed her to a sexually transmitted virus that can cause cancer.

The low rate of free will oriented responses may be due to the type of evil events we asked interviewees to explain. Identifying an unambiguous cause of cancer 
is difficult, since it typically results from a complex combination of genetic, environmental, and lifestyle contributors. Unsurprisingly, cancer resulting from vague or unknown combinations of causes is more difficult to explain in terms of personal volitional choices than some other evils. By asking "why" cancer occurs, we asked our interviewees to explain a phenomenon that is a paradigm example of natural rather than moral evil.

In contrast, if interviewees had been asked to explain the causes of suffering from violent crime-a paradigm moral evil stemming apparently from the free actions of humans-we would have expected more responses focusing on personal choice and free will. Similarly, if we had interviewed cancer sufferers who had all received cancer diagnoses with a well-known connection to behavioral causes-such as lung cancer with its well-known connection to tobacco usage-we might have found a greater preoccupation with free will explanations. ${ }^{12}$ Yet, our mix of cancers sufferers did not have a high proportion of interviewees suffering from cancers with a widely known environmental or behavioral trigger. In general, cancer does not appear to stem directly from free choices-either the sufferer's or someone else's. If free will plays a role in explaining such suffering of most cancers, the connection is typically unclear, indirect, unseen, or is only one of several contributing factors.

Another possible explanation for the low number of interviewees offering free will explanations for cancer may lie in the difference between asking for an explanation for suffering in general and asking for an explanation for specific instances of suffering. Perhaps, free will is an attractive explanation for the broad and general existence of suffering because it identifies a general feature of humanity. Instead of asking for an explanation of suffering more generally, our interviews asked for an explanation of a narrow, specific instance of suffering. Furthermore, the specific instance of suffering to be explained was one that did not have an unambiguous, direct connection to free choice. Accordingly, few interviewees even pondered whether their own health related, dietary, or similar lifestyle choices had a role in bringing about cancer.

A third reason for the low rate of free will responses may lie in a structural difference between free will explanations for evil and several other responses. Moral, relational, and spiritual growth responses focus on beneficial results from suffering. As such, the causal connections between suffering and the benefits stemming from suffering may be more salient to the sensibilities of the lay person. In contrast, free will responses focus on the origins of suffering rather than suffering's results. But, since the precise cause of any particular person's cancer are typically difficult to identify in terms of a single event or choice, justifications of suffering focusing upon the freely chosen nature of such events will be less salient and meaningful to the layperson.

While only a minority of our interviewees cited the importance of free will as part of their explanation for their cancer experience, it is unclear whether this fact should count as evidence against free will explanations of evil or whether it is merely neutral data. While a lack of observed moral, relational, and spiritual growth would

\footnotetext{
${ }^{12}$ Only one of our interviewees was diagnosed with lung cancer. She did express free will meanings in the explanation of her cancer, but the need to trust God in cancer was her primary explanation.
} 
seem to count against theodicies focused on those results from evil, it is unclear what sort of distinct experience we would expect cancer sufferers to have if free will plays an important role in explaining evil.

\section{Representative Quotation about Free Will and Cancer}

Interviewer: At any point during your journey have you experienced any tension between your Christian beliefs and the cancer diagnosis that was an issue for you?

Interviewee: No. I don't think so.... I can remember thinking you know 'Why God?'. . .. But it was really when I said 'Why God?' I was like 'Was there something that I did that I, you know, was I not taking care of myself the way I should have?' Um 'Did I allow all of that radiation-mammogram radiation when I had the. . when car accident happened ... was that ... You know, all these things. What could I have done?'-[Participant 5]

Interviewer: . . . if someone were to ask you why do you think you got cancer, what would you answer?

Interviewee: Stress. From my ex-husband, yea and raising an autistic child. No doubt about it. I have no doubt about it.

Interviewer: Alright. What do you see as God's role in you're having cancer?

Interviewee: Oh he has no role in it. No, it's just the fallen world, it has disease in it so you know I was in a very stressful not very good marriage with an autistic child ... you know $85 \%$ of families with autism split up. That's the way it is. My ex-husband probably is also autistic.... he would definitely be on the spectrum. - [Participant 25]

Interviewer: What role would you say God had in you getting cancer?

Interviewee: What role did God have?

Interviewer: Mhmm.

Interviewee: ... I don't blame God for it. It just uh probably just my lifestyle. I was doing things ... that are not necessarily helpful. You know.... sugar is very addictive. ... sometimes I don't get enough sleep or I don't get enough exercise or I'm lazy. ... I can't say exactly what caused the cancer. Neither can the doctors. Well certainly smoking did not help. I don't drink. I've never drank ... I drank a lot when I was ... when I was in my twenties but that didn't last long. Used a few drugs but not a lot. I was always kind of afraid of getting addicted to things. But I got addicted to nicotine at a young age ... - [Participant 28] 


\section{Discussion of Result: Few Interviewees Find Meaning in Viewing Cancer as Punishment}

One possible explanation for suffering that we have not yet discussed at length is the possibility that suffering is a divine punishment for personal sin, evil, or immorality. This explanation would presuppose the existence of free will since punishment would result from misuses of free will. On this view, punishing sin and upholding justice would constitute greater goods that would justify suffering in the world. Yet, suffering is not merely the logical consequence of certain foolish or immoral actions committed by ourselves or others, which are a natural result of misused free will and the physical laws governing this world. Instead, suffering would be an intentional, divinely sanctioned active punishment against rule breakers.

We have given this explanation little attention for two reasons. First, there is little contemporary scholarship advocating a theodical explanation of suffering as punishment, although William Alston does briefly argue for its plausibility (Alston 1996). However, historically there have been some who have preferred this explanation, but in contemporary Judaism and Christianity it is a view most closely associated with Job's presumptuous comforters, whose views are directly rejected in the Biblical text (Job 42:7). Furthermore, the values system required to endorse statement $3 \mathrm{e}$ is generally viewed as less plausible than the values systems required to endorse statements $3 \mathrm{a}-3 \mathrm{~d}$.

The second reason we do not give this viewpoint more attention is that in our interviews we only had four interviewees who made any mention of the possibility that cancer was a kind of divine punishment for them. Furthermore, only one of the four actually endorsed the view that their cancer was a kind of punishment.

\section{Representative Quotation Concerning Cancer as Punishment}

... I read the Old Testament and I go, 'Foof, boy He is a punitive God.' So, I felt because of my Catholic background and some of my own twisted thinking that this was punitive. This was a punishment for something. Not knowing what it was but definitely a punishment and that He was really mean. And that's where the bargaining came in.... I thought, “Gosh, if Ido all this other stuff, why won't you cleanse me of this punishment?" And that's where the bargaining came in. Okay, I'll quit meat. Okay, I'll quit alcohol. I'll quit being critical. Never went away. So, it was all part and parcel to how I viewed, I viewed the cancer as a punishment for being bad. - [Participant 10] 


\section{Discussion of Result: High Number of Interviewees Find Meaning in Trusting God in Suffering and Acknowledging Mystery.}

$79 \%$ of our interviewees expressed a sense of mystery concerning their cancer experience or said it was important to respond with trust in God during the ambiguities of their cancer experience. For $48 \%$ of our interviewees, it was the theme mentioned most frequently. However, acknowledging a degree of mystery in suffering is also compatible with a simultaneous humble endorsement of one of the traditional explanations for why God allows evil. For example, one may speculate that God allows evil to bring about richer kinds of spiritual growth than would otherwise be possible while simultaneously perceiving some degree of mystery concerning why God allows suffering. Most of the interviewees primarily endorsing a Trust God/Mystery explanation of their experience also had additional theodical explanations in their interviews. Only $7 \%$ of our interviewees held mystery as the sole explanation for their experience.

In contrast to interviewees' lack of focus upon free will explanations for their cancer, a considerable majority of our interviewees expressed this idea at least once. Perhaps, the fact that our interviews focused upon instances of cancer stemming from unknown causes resulted in interviewees eschewing free will explanations while encouraging responses centered on mystery and trust in God. Free will explanations are attractive answers for suffering when there is easily accessible knowledge of a causal connection between human action and the suffering in question. In such cases, answering the question of why such a tragedy occurred is straightforward: because a human agent freely made foolish or malevolent choices. Yet, in the absence of such easily identifiable cause and effect, sufferers are left with more abstract, speculative answers and this ambiguity encourages appeals to mystery.

In at least one sense, there is nothing surprising about the high number of interviewees offering answers for suffering that centering on mystery. Since humans-both individually and collectively-have limited knowledge and some experiences are disorienting, it is natural to respond to unexplained experiences with a sense of mystery. Cancer is often one such experience. It is difficult to trace most instances of cancer to specific clear and unambiguous direct causes. Furthermore, during treatment cancer patients face uncertain results. Even when remission is achieved, whether cancer is truly cured or only temporarily defeated is uncertain for years to come. Therefore, it is unsurprising that cancer sufferers find the experience mysterious and difficult to understand.

Given a disorienting, inscrutable experience of suffering and a previously existent belief in a good God, it is unsurprising that a large proportion of our interviewees responded to the ambiguities of their cancer experience with trust in God. The simplest way to reconcile the existence of God with the reality of suffering is to respond with trust in God while being agnostic concerning the reasons for suffering. This is roughly an endorsement of statement three from our initial discussion of the problem of evil. All the Christian needs to accept is that there are 
good, if unknown, reasons for their suffering. Furthermore, it is unsurprising that divine motives for allowing such suffering would be unknown since one would expect there would be a vast number of important matters that would be known to an all knowing God that would not be known to us.

It is difficult to interpret the implications of this interview result into one clear response towards the problem of evil. One possible interpretation is that these responses imply that our interviewees held a generic version of theodical statement 3 , which claims that God has a good, but unknown reason for allowing evil. A competing interpretation is that our interviewees intuited something similar to the skeptical theist position that, "humans are in no position to judge directly that an omnipotent and omniscient being would be unlikely to have a morally sufficient reason to permit the evils we find in the world" (Draper 1996, 176). On this view, it is simply not reasonable to expect clear answers to questions like, "why would a good God allow the evil of cancer?" All answers to such questions are necessarily speculative, as are atheological responses attempting to derive evidence against the existence of God from such experiences. Most likely, our interviewees actually held a range of views with some closer to the generic theodicy view, while others were closer to skeptical theism.

\section{Representative Mystery/Trust Response}

Interviewer: ... During your whole cancer journey have there been moments when you've experienced some tension between your Christian beliefs and your cancer diagnosis?

Interviewee: No not at all.

Interviewer: You seem very confident in that.

Interviewee: Yes, because I know there's a reason for this. Maybe I might not understand but I know the Lord has put me here for that reason. - [Participant 3]

Interviewer: So, what role if any do you feel like God played in your having cancer?

Interviewee: Well, if ... if He did play a role in me having cancer, it was to prepare me for a purpose that he has for me.

Interviewer: Ok.

Interviewee: Whatever that is. And um, you know, that I need to find it.-[Participant 5]

$---$

Interviewee: ... I don't really have an answer as to why I think I got cancer. I really, really don't but do I have a closer relationship now with God? Yes. Do I understand 
more about how the Holy Spirit dwells in me? Do I understand ... where my home really lies? Yes. But do I know why I got cancer? No.-[Participant 8]

\section{Discussion of Result: 69\% of Interviewees Identified Moral Growth Resulting from Their Cancer Experience}

More than two-thirds of interviewees identified moral growth resulting from their cancer experience. For $10 \%$ it was the predominant meaning they attributed to their experience. The observation that suffering brings about moral growth is consistent with the heart of John Hick's soul-making theodicy, which claims that God allows suffering because it is necessary for superior kinds of moral development. Common types of moral growth reported by our interviewees included: a broader and more accurate perspective on what is important in life, reduced materialism and selfishness, increased commitment to, increased appreciation of, and increased prioritization of others' well-being.

It has long been suggested that there is a close connection between moral growth and suffering. For example, Eleonore Stump cites Aquinas's claims that, "As water extinguishes a burning fire, so tribulations extinguish the force of concupiscent desires, so that human beings don't follow them at will" and "Since pains are a sort of medicine, we should apparently judge correction and medicine the same way. Now medicine in the taking of it is bitter and loathsome, but its end is desirable and intensely sweet. So discipline is also. It is hard to bear, but it blossoms into the best outcome" (Stump 1996, 55).

Suffering can remind the sufferer of the temporary nature of earthly goods including life itself and cause one to reconsider priorities. Furthermore, it allows the sufferer to receive care from those serving him during this time of need and dependency. While there is no guarantee that any particular individual will embrace moral growth in such circumstances, most of our interviewees appeared to do so.

Notably, more interviewees claimed that their cancer experience brought about moral progress [69\%] than either relational [62\%] or spiritual growth [45\%]. Perhaps, our interviewees conceptualized the moral realm of life more broadly than the relational or spiritual realms. Plausibly, every action has moral import. The reasons for holding this view would vary widely depending upon one's normative ethical theory, but a wide range of theories are compatible with the idea that every action is morally significant. One may believe that: every action either maximizes good consequences or fails to do so, every action either fulfills one's moral duties or fails to do so, every action either instantiates virtuous character or fails to do so, etc.

In contrast, the spiritual realm of life is sometimes conceptualized narrowly, in terms of explicitly religious activities. Given that the contemporary mindset typically holds to a strong sacred/secular dichotomy many interviewees may consider the activities relevant to spiritual progress to be rather narrow. Similarly, relational progress is a narrower category in that it might be viewed strictly in terms of direct social interactions rather than broader attitudes. So, someone might think "I progressed morally because I am less preoccupied with acquiring wealth, but I didn't 
progress spiritually because I still go to church and pray about the same as before, and I didn't progress relationally because I still have the same number and kinds of relationships that I had before cancer."

\section{Representative Quotations from Moral Growth Narratives}

Interviewer: Do you think your view of yourself or your character has changed from before to after [the experience of having cancer]?

Interviewee: “. . I was always a pretty worldly guy and drank too much, ran around too much, just uh you know-and I was in business. I was not a nice person if I really reflect on it in that I would walk through brick walls to get my way and I didn't care how many bodies I left in my path in my way as long as I won.... Today my thought process is diametrically opposed to anything I ever did in my previous life. I find myself going out of my way to be nice to strangers. I find myself giving somebody else the right of way through a traffic sign when it's my turn to go. And I just you know I mean it sounds like little things but it's built you know my character and I'm slow to anger where I used to have a hot temper. I don't anymore. I listen intently to the other guy and analyze and I'm more reflective. ... I'm a totally different person."[Participant 17]

Interviewee: . . .I think you kinda put on a different pair of glasses when you walk through painful things. And uh I think it helps you to be-, well I thought I was empathetic before and I think the Lord has kinda given me a tender heart to begin with and that can be a real positive but it can also be really tough, it can be tough at times.-[Participant 13]

Interviewee: you know, all that's happened is, you know breast cancer and you know. .. It's like one tumbleweed after another and it's like well, then God is telling me He's preparing me that there's something that I need do ... He's saying 'Don't sit back and be selfish and look for something for you.' He's saying 'Go out and do something with your life. The life I've given you.' - [Participant 5]

\section{Discussion of Result: 62\% Identified Relational/Communal Growth Resulting From Their Cancer Experience}

Well over half of our interviewees associated significant relational or communal growth with their cancer experience. For ten percent relational growth was the predominant narrative from their experience. Slightly fewer interviewees reported relational growth than moral growth, but more reported relational growth than 
spiritual growth from their cancer experience. Yet, the fact that most interviewees experienced some relational or communal growth appears to give modest corroborating evidence for theodicies based in improved relational goods. One could also argue that the mere opportunity for such relational improvements is adequate for theodicy, even if not everyone took advantage of the opportunity.

It is unsurprising that suffering can be an occasion for relational growth since it can cause individuals to seek out the support of others. As others provide emotional and practical support in times of hardship, this helpfulness can result in improved relationships and greater mutual appreciation. However, suffering may also exacerbate interpersonal problems in dysfunctional relationships or result in disillusionment if sufferers are denied desired support from others.

Fortunately, there are reasons to hope that these cancer sufferers would be well cared for, which would help improve these relationships. Within the Christian community, visiting and caring for the sick is a priority and a direct biblical command (Matthew 25:36). ${ }^{13}$ In times of suffering, these relational networks based in religious community could be greatly beneficial. In general, natural empathy within previously existing relational networks can help lead to increased support. As Alasdair MacIntyre cites Mencius's observation that, "all human beings have the mind that cannot bear to see the sufferings of others ... when human beings see a child fall into a well, they all have a feeling of harm and distress." (MacIntyre 1999, 123) Observing others who are suffering can trigger one's natural empathy with the sufferer. Accordingly, help in times of suffering can bind people together. As caregivers provide increased time and commitment to the sick it is common that the sufferers increase their appreciation for them and commitment to them. As the sufferer become more aware of his need for others, it is natural to become appreciative. Despite the individualism of American culture, times of suffering make people more aware of their actual dependence upon others.

\section{Representative Relational/Communal Meaning Quotation}

Interviewer: What were your interactions with God like, around this time of diagnosis?

Interviewee: I was a little angry to begin with. You know, why me? And uh, you know it got to a point where I said "why not?" you know. And I know I was able to minister to other people. Um, I even told the pastor that I worked for that, um, I've had so many more people call in and saying they've gotten a cancer diagnosis. So, I was able to talk with them and pray with them on the phone. So it was kind of a help for me too, knowing that I wasn't going through it alone. And I was able to help other people too.-[Participant 1]

\footnotetext{
${ }^{13}$ This teaching has also been a traditional motivation for the Christian founding of hospitals. The socio-relational benefits of religious involvement have been long established in general, religious participants enjoy greater social support due to their religious communities than non-participants.
} 
Interviewer: How else do you think you changed?

Interviewee: I think just enjoying people more. That uh you know, enjoying their friendship more and taking things for granted. That you know, like getting together with my buddies or something and uh you know, we talk about good things that you know affects our lives and well, I'm always away trying to get them to come to church or do something but I don't wanna press the issue because they get kinda turned off by that.-[Participant 9]

\section{Discussion of Result: 45\% Identified Spiritual Growth Resulting From Their Cancer Experience}

Nearly half of our interviewees associated spiritual growth with their cancer experiences and it was the predominant narrative for $17 \%$. While this is a large group, it was less than half of the total group of interviewees and smaller than either those reporting moral or relational growth. However, our interviewees were more likely to treat spiritual growth as their predominant cancer narrative than either moral or relational growth. These interviewees volunteered specific examples of spiritual growth they attributed to their cancer experiences. By spiritual growth-as opposed to moral or relational growth-we looked for direct references to the interviewee's faith, view of God, or spiritual commitments. Some interviewees spoke of increased faith and confidence in God. Others spoke of the increased importance of God in their lives. One spoke as if the cancer experience transformed his religious life from a trivial part of life to the central concern.

A number of features of the cancer experience seemed to make it an ideal opportunity for spiritual development. The existential threat of cancer provides opportunity to reflect upon several ultimate questions addressed by Christianity: is there hope after this life? Are there things that matter more than life itself? Is there a way to transcend physical suffering? The physical pain and existential threat of cancer can encourage the sufferer to hope in the immaterial God and the afterlife rather than earthly well-being.

Cancer can make the sufferer more aware of the shortness of life and seek hope in something more eternal. It could also cause them to identify with Christ as a paradigm of hope in the face of suffering and death. Furthermore, the disruptions cancer makes to one's schedule provide special opportunities to reflect upon ultimate questions. There are also many hospital chaplaincies and church ministries that emphasize visiting the sick. Meanwhile, the pain of the cancer experience can undermine physical pleasures and typical amusements that might compete with Christian priorities. This result seems to give some corroborating experiential support for theodicies rooted in the importance of developing a deeper relationship with God, such as the model advocated by Eleonore Stump. Furthermore, it may even be the case that the mere opportunity such suffering provides for spiritual growth may be a valuable good. 
While a significant portion of our interviewees reported spiritual growth the number was smaller than the other categories of personal growth. This result may be due to the aforementioned possibility that the category of spiritual growth might be difficult to quantify. There might be a tendency to reduce the category of spiritual growth to specific religious activities and thereby only measure it in terms of increased participation in such activities. For example, it is completely possible for a cancer survivor to claim: I'm less selfish than I was before cancer, and I value my family more, but I don't think I grew spiritually because I still pray for about 15 minutes a day and attend church three times a month, exactly like before I had cancer.

Furthermore, even if one resists the tendency to conceptualize spiritual growth in terms of specific, limited external activities, there may be another difficulty. Spiritual growth can be a vague, abstract, unempirical notion and difficult to measure since it may be a qualitative rather than quantitative concept. Accordingly, it would be difficult to know how genuine spiritual growth would manifest itself in human experiences, especially since our study conceptualized it distinctly from moral and relational growth. Spiritual growth might make someone feel worse about themselves as their moral flaws become more obvious as they are united with a perfect deity. Spiritual growth might make someone feel joyous as they grew in relationship and unity with a loving deity. Spiritual growth might make someone sad as they become aware of the comparative emptiness of earthly life. An experience with such a wide range of potential effects might be difficult for interviewees to conceptualize appropriately.

Finally, it is possible that several of the "trust God in suffering/mystery" responses could have been counted as "spiritual growth" responses instead. If trusting God is of great spiritual value, then perhaps we created a category of "spiritual growth" that was unnecessarily narrow. Given that the virtue of faithalong with hope and love-is one of three traits that have traditionally been attributed the highest value as marks of authentic spirituality in the Christian tradition, it is arguable that our categorizations understate the number of spiritual growth themes in our interviews.

\section{Representative Quotation Concerning Spiritual Growth During Cancer Experience}

Interviewer: You have mentioned how much your life has changed from before the cancer until now.... Has your view of God changed from before to after?

Interviewee: . . . before God was sort of on the periphery of my life at best. ... Since my illness ... God didn't recede into the past. He stayed very strong and present in my life and that was because I made the effort. ... "Draw Nearer to God and He will draw nearer to you." So that's what I've done. I've drawn nearer to Him since the first cancer.-[Participant 15] (with a terminal diagnosis) 


\section{Objection Considered: Finding Growth or Meaning in Suffering May Constitute Unhealthy Psychological Denial}

Instead of a healthy and hopeful phenomenon, someone might argue that our results actually illustrate a psychologically unhealthy defense mechanism. Were our interviewees simply denying the horrifying realities of their experiences? Were they ignoring their suffering in light of some comparatively modest or even entirely imaginary "bright-side" to the situation? Beginning with Sigmund Freud, psychologists have studied the ways in which people use defensive strategies to cope with overwhelming anxiety and fear. One of these strategies, denial, has been described as "the simple refusal to face certain facts."(Baumeister et al 1998, 1107) The idea that denial might be invoked in response to health-related threats can be traced back to Kubler-Ross's proposal that denial is a stage that is passed through after learning that one's illness will be fatal (Kubler-Ross 1969). While potentially useful in the short run, denial does not seem to work particularly well as a defense against anxiety over time (Janoff-Bullman 1992). For example, Carver et al. found that denial was associated with greater distress in breast cancer patients (Carver et al 1993).

One powerful depiction of unhealthy denialism does not come from an academic text, but from columnist Barabara Ehrenrich's account of her cancer experience in Bright-Sided: How Positive Thinking is Undermining America. She recounts, "Breast cancer ... did not make me prettier or stronger, more feminine or spiritual. What it gave me ... was a very personal, agonizing encounter with an ideological force in American culture that I had not been aware of before-one that encourages us to deny reality, submit cheerfully to misfortune, and blame only ourselves for our fate" (Ehrenrich 2010, 43-4).She goes on to claim that such brightsiding, “. . . requires deliberate self-deception, including a constant effort to repress or block out unpleasant possibilities and 'negative' thoughts"(Ehrenrich 2010, 5).

Is it possible that our interviewees were simply bright-siding? Were they simply denying the negative realities of their suffering and blocking out negative thoughts? In general, the answer would seem to be no.

Merely expressing positivity in the face of suffering or identifying growth in traumatic circumstances is not enough to constitute psychological denial or brightsiding. A constitutive element of these unhealthy phenomena, as noted earlier, is the repression or ignoring of unpleasant possibilities. In contrast, a considerable majority of our interviewees did not ignore unpleasant aspects of their experiences, but instead expressed negative emotions and aspects of their experiences alongside the positive emotions and meanings associated with their experiences. Out of our 29 interviewees, 24 (83\%) described at least one negative emotion associated with their experience alongside the positive. Fear and anger were the most common negative emotions associated with our interviewees' cancer experiences. Fear was expressed by 22 of our interviewees, a considerable majority (76\%). Most of these 22 described or mentioned fear 1-3 times during the interview, but we did have participants who described fearful emotions as many as 13 times. 
Anger was another common negative emotion among our interviewees. It was mentioned by 10 (34\%) of our interviewees. Note further that this anger was typically directed outward at God, the situation, or the world, rather than themselves. Only 5 $(17 \%)$ of our interviewees expressed no negative emotions concerning their cancer experience. Since a considerable majority of our interviewees appeared to acknowledge the negative aspects of their experience including expressing negative emotion alongside the positive, we do not believe that they were generally in denial or "bright-siding."

In the opinion of the experienced clinical psychologist who performed the interviews, only one of the interviewees appeared to simply deny the serious negative realities of his cancer experience. This participant held to a list of biblical promises that he would claim daily that he believed ensured his physical health. This interviewee was the anomalous case expressing genuine denial of the serious dangers of his situation, while the other 28 expressed healthier, more balanced attitudes.

\section{Example of Unhealthy Denialism in Cancer}

Interviewee: . . . you know by Jesus' stripes we were healed. Christ prepaid this disease. Not only saved us from sin but He also saved us our iniquities and our infirmities. . . . Jesus Christ paid a big price. He already prepaid the price of my disease.-[Participant 17]

\section{Conclusion}

The near universal experience of evil and suffering has made the problem of evil a perennial philosophical issue of great interest. Just as the experience of suffering does much to establish the significance of the problem of evil, how sufferers make sense of their own suffering is similarly relevant to this debate.

Our interviews demonstrate that many lay Christians intuit a position similar to that of either skeptical theism or a very generic undefined theodicy. 'Trust God in Mystery" was the most frequently mentioned theme from our interviewees with 79\% making at least some reference to it and $47 \%$ holding it as the primary meaning of their experience. Furthermore, our interviewees found far less tension between their theistic beliefs and their experience of suffering than philosophers with 52\% perceiving no tension that would even be in need of a theodicy to reconcile them. Two possible ways to interpret these data are: 1) That our interviewees believed that there is some unspecified theodical way to reconcile God's goodness with their cancer experience, but could not identify the specific reason or 2) Our interviewees did not think they were in a proper position to judge what God's reasons for allowing cancer might be but believed that the proper response was to trust God despite their limited understanding of the situation. The first interpretation suggests that our interviewees intuited a very generic theodical explanation for their cancer experience, while the second interpretation would be a variation of skeptical theism. 
A second significant finding is that $86 \%$ of our interviewees volunteered at least one distinct example of moral, spiritual, or relational growth resulting from their cancer experience. In at least this way, the experience of our cancer sufferers was similar to what "moral soul-making," "relational growth," and "spiritual growth" theodicies would predict, thereby increasing the plausibility that there are indeed benefits from experiencing suffering that might serve as a justification for God allowing it. Yet, these benefits were only the predominant theme in $37 \%$ of our interviews. This data might also be compatible with the idea that God has many varied reasons for allowing suffering rather than a single one. ${ }^{14}$

Obviously, this data does not resolve the problem of evil. Yet, these interviews documenting the experiences and reflections of actual religious sufferers are important data that is worth examining by philosophers and theologians investigating the problem of evil and suffering.

${ }^{14}$ A special thanks to Hudson Lee who did the coding for our interviews. Thanks also to Chris Tweedt, Helen De Cruz, and an anonymous referee, who provided helpful comments on earlier versions of this paper. A special thanks to Dr. Silverman's Research Apprentice Lauren Chadwick, who also helped with proofreading and commenting on a draft of this paper. This study and paper have been made possible by a grant from The Council for Christian Colleges and Universities. 


\section{References}

Alston, William. 1996. "The Inductive Argument From Evil and The Human Cognitive Condition," in The Evidential Argument from Evil. Edited by Daniel Howard-Snyder. Indiana University Press. 97-125.

Augustine, Confessions. 1960. Translated by Jack K. Ryan. Doubleday.

Baumeister, Roy F., Karen Dale, and Kristin L. Sommer. 1998. Freudian Defense Mechanisms and Empirical Findings in Modern Social Psychology: Reaction Formation, Projection, Displacement, Undoing, Isolation, Sublimation, and Denial. Journal of Personality, 66(6): 1081-1124.

Carver, Charles S., Christina Pozo, Suzanne D. Harris, Victoria Noriega, Michael F. Scheier, David S. Robinson, Alfred S. Ketcham, Frederick L. Moffat Jr., and Kimberley C. Clark. 1993. "How Coping Mediates The Effect of Optimism on Distress: A Study of Women With Early Stage Breast Cancer," Journal of Personality and Social Psychology, 65. 375390.

Copeland, Kenneth, and Gloria Copeland. 2012. Healing Promises. Harrison House Publishers.

Draper, Paul. 1996. "The Skeptical Theist," in The Evidential Argument from Evil. Edited by Daniel Howard-Snyder. Indiana University Press. 175-192.

Ehrenrich, Barabara. Bright-Sided: How Positive Thinking is Undermining America. 2010. Henry Holt and Co.

Hall, M. Elizabeth Lewis, Laura Shannonhouse, Jamie Aten, Jason McMartin, and Eric Silverman. 2018. "Theodicy or Not? The Spiritual Struggles of Evangelical Cancer Survivors" Journal of Psychology and Theology, 47 (4). http://journals.sagepub.com/doi/abs/10.1177/0091647118807187?journalCode= ptja

Hick, John. 2010. Evil and the God of Love. Palgrave MacMillan.

Janoff-Bullman, Ronnie. 1992. Shattered Assumptions: Towards a New Psychology of Trauma. Free Press.

Kant, Immanuel. 2002. The Critique of Practical Reason. Translated by Werner S. Pluhar. Hackett.

Krippendorff, Klaus. 2013. Content analysis: An Introduction to its Methodology (3rd ed.). Sage.

Kubler-Ross, Elisabeth. 1969. On Death and Dying. Macmillan.

Landis, J. Richard, \& Koch, Gary G. 1977. "The Measurement of Observer Agreement for Categorical Data." Biometrics, 33, 159-174. http://dx.doi .org/10.2307/2529310

MacIntyre, Alasdair. 1999. Dependent Rational Animals. Open Court Publishing. 
Mackie, John. 1982. The Miracle of Theism. Oxford University Press.

Plantinga, Alvin. 1974. God, Freedom, and Evil. William B. Eerdmans Publishing Company.

Schreier, Margrit. 2012. Qualitative Content Analysis in Practice. Sage.

Sontag, Susan. 2001. Illness as Metaphor and Aids and its Metaphors. Picador.

Stump, Eleonore. 1993. "Aquinas on the Sufferings of Job," in Reasoned Faith. Edited by Eleonore Stump. Cornell University Press. 328-357.

2012. Wandering in Darkness: Narrative and the Problem of Suffering. Oxford University Press, 2012.

Van Inwagen, Peter. 1996. "The Problem of Evil, the Problem of Air, and the Problem of Silence" in The Evidential Argument from Evil. Edited by Daniel Howard-Snyder, Indiana University Press. 151-74.

Wykstra, Stephen J. 1984. "The Humean obstacle to evidential arguments from suffering: On avoiding the evils of 'appearance'". International Journal for Philosophy of Religion 16 (2):73 - 93.

. 1996. "Rowe's Noseeum Arguments from Evil," in The Evidential Argument From Evil. Edited by Daniel Howard-Snyder. Indiana University Press. 126-150. 